\title{
Laboreal
}

Volume $8 \mathrm{~N}^{\circ} 2$ | 2012

A antropotecnologia, ferramenta ou engodo?

\section{A antropotecnologia, ferramenta ou engodo?}

La antropotecnología, ¿herramienta o trampa?

L'anthropotechnologie, outil ou leurre?

Anthropotechnology, tool or bait?

\section{Alain Wisner}

\section{(2penEdition}

\section{Journals}

\section{Edição electrónica}

URL: http://journals.openedition.org/laboreal/6516

DOI: $10.4000 /$ laboreal.6516

ISSN: 1646-5237

\section{Editora}

Universidade do Porto

\section{Refêrencia eletrónica}

Alain Wisner, "A antropotecnologia, ferramenta ou engodo? », Laboreal [Online], Volume 8 N² | 2012, posto online no dia 01 dezembro 2013, consultado o 24 setembro 2020. URL : http:// journals.openedition.org/laboreal/6516; DOI : https://doi.org/10.4000/laboreal.6516

Este documento foi criado de forma automática no dia 24 setembro 2020.

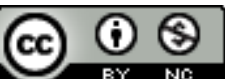

Laboreal está licenciado com uma Licença Creative Commons - Atribuição-NãoComercial 4.0 Internacional. 


\title{
A antropotecnologia, ferramenta ou engodo?
}

\author{
La antropotecnología, ¿herramienta o trampa? \\ L'anthropotechnologie, outil ou leurre? \\ Anthropotechnology, tool or bait?
}

Alain Wisner

\section{REFERÊNCIA}

Artigo original: Wisner, A. (1984). L'anthropotechnologie, outil ou leurre ? Technologies, Idéologies, Pratiques, 5, 28-59.

1 A expressão "antropotecnologia" é proposta para designar a utilização simultânea das ciências da natureza e da sociedade para processar da melhor forma as transferências de tecnologias nos países em vias de desenvolvimento industrial. A natureza e a prática da ergonomia são descritas, bem como as diversas modalidades de transferência, a partir de estudos realizados em quatro continentes. Todavia, a tentativa de descrição da antropotecnologia não pode escapar ao cunho de modelos ideológicos e políticos que devem ser relembrados. Uma tentativa de desenvolvimento de uma metodologia geral é proposta para conhecer melhor a realidade do país comprador e prever as dificuldades nas diferentes etapas da transferência.

2 A utilização das ciências da natureza e da sociedade para a realização da transferência satisfatória das tecnologias para os países em vias de desenvolvimento industrial (PVDI) apareceu-nos progressivamente como sendo indispensável e propusemos a expressão "antropotecnologia" para esta arte eventual. o próprio conceito de antropotecnologia resulta do de ergonomia cujas natureza e prática têm de ser, portanto, descritas antes de mais. A necessidade da antropotecnologia surgiu ao analisar os êxitos e insucessos das modalidades bastante diversificadas de transferência de tecnologias realizadas no mundo, durante estadias em cerca de vinte países de quatro continentes e graças aos 
estudos realizados nos respectivos países por estudantes que preparam um doutoramento de Ergonomia. A natureza das transferências observadas e as condições financeiras e comerciais das respectivas realizações são bastante diversificadas, embora ainda existam mais diferenças entre as situações de acolhimento realizadas nos países compradores. São situações que a antropotecnologia tenta descrever graças aos conhecimentos e métodos das diversas ciências da natureza e da sociedade. Todavia, essa descrição apenas pode corresponder a modelos ideológicos e políticos evidentes ou ignorados que devem ser relembrados : não pode ser descrita da mesma forma uma fase da industrialização quer corresponda a uma política de destruição da sociedade tradicional ou a uma tentativa de conservação da mesma, quer seja realizada por uma empresa multinacional graças à tolerância do governo ou quer pertença a um plano destinado a aumentar a independência nacional. Todavia, poder-se-á pensar que, em todos estes casos, pode ser desenvolvida uma metodologia geral para conhecer melhor o país comprador e prever, através de uma comparação, as principais dificuldades de funcionamento que terão de ser resolvidas aquando das diferentes etapas da transferência.

\section{I.1 - Uma ergonomia para a transferência de tecnologia?}

3 Em 1972, a NATO (civil) reuniu em Oosterbeek (Países Baixos), sob a direcção de Chapanis (EUA) e de Jong (Países Baixos), 44 investigadores para analisar o tema das variáveis nacionais e culturais na Human Factors Engineering (Engenharia dos Factores Humanos). Entre as pessoas presentes, apenas seis eram oriundas de um país fora dos Estados Unidos e Europa Ocidental (Índia, Israel, Japão, Nigéria, África do Sul). Na sequência deste colóquio, foi publicado por Chapanis (1975) um livro intitulado Ethnic Variables in Human Factors Engineering (Variáveis Étnicas na Engenharia dos Factores Humanos). Trata-se de um conjunto de elevado nível mas bastante significativo na sua composição: quatro textos incidem sobre problemas puramente militares, outros quatro resultam de grandes empresas multinacionais, duas das quais relacionadas com a produção e duas com o produto, três outros textos referem-se à transferência de tecnologia entre países desenvolvidos, seis textos são de carácter geral quer a título introdutório quer como dados fundamentais ou princípios. Apenas três textos estão relacionados com os problemas de ergonomia industrial conforme enfrentados concretamente, e até mesmo dramaticamente, pelos países em vias de desenvolvimento industrial para os quais é realizada a transferência de tecnologia.

4 A análise do livro de Chapanis evidencia diversos aspectos de uma determinada concepção da ergonomia para a transferência de tecnologia para os países em vias de desenvolvimento industrial :

- as investigações são efectuadas pelos investigadores dos países vendedores ;

- as diferenças a ter em conta entre países vendedores e compradores são consideradas no título como sendo de natureza "étnica" e não "climatérica", "demográfica" ou "económica" ;

- os temas são os da ergonomia mais restrita (factores humanos na engenharia).

De facto, os problemas abordados neste livro são os seguintes :

- As diferenças antropométricas. Sabe-se actualmente que essas diferenças são importantes entre a população do sudeste asiático (altura média inferior a 1,65 m) e a população do norte 
da Europa e da América (altura média superior a 1,75 m) e que não são significativas entre as populações mediterrâneas do sul da Europa e do norte de África $(m=1,68 m+o u-0,02 m)$ (Sahbi, 1982).

- As diferenças de forças físicas. O estado nutricional e de saúde (tuberculose, parasitoses) desempenha, pelo contrário, um papel crucial. Por exemplo, Wyndham constata que a capacidade física média dos aldeãos bantos que chegam para trabalhar nas minas de ouro de África do Sul é igual à metade do que se espera de um mineiro europeu. As soluções encaradas neste caso não são do tipo ergonómico : elimina-se a metade dos candidatos e os que ficam são tratados e bem alimentados.

- As diferenças de psicologia fundamental. Verhagen e respectivos colaboradores (1975) (Bélgica) demonstram que os estereótipos (respostas motoras prováveis em função das variações de um indicador) são idênticos nos casos belga, congolês e magrebino.

- As diferenças linguísticas. São propostas duas soluções para responder às grandes dificuldades associadas às diferenças linguísticas. Voets (1975) (Países Baixos) recomenda ensinar aos trabalhadores "a linguagem do dia-a-dia falada na empresa para que possam executar as suas tarefas de acordo com os pedidos da empresa e para poderem conversar, em neerlandês, com os seus responsáveis e colegas sobre a natureza e qualidade do seu trabalho". Esta concepção levanta várias questões graves relacionadas com a linguagem : será que a linguagem formal relacionada com o trabalho teórico permite comunicar acerca da realidade do trabalho expressa através de um vocabulário e sintaxe informais ? Será que o essencial da linguagem não se encontra no que inicia o enunciado formal ? Não haverá aí, de alguma forma, uma espécie de extensão do taylorismo para o campo da linguagem ?

6 A abordagem de Sinaïko e respectivos colaboradores (1975) é totalmente diferente, pois demonstraram fenómenos fundamentalmente importantes, recorrendo a uma situação histórica bem específica, ou seja, a reparação do material militar americano por trabalhadores vietnamitas: existe uma relação significativa entre o número e a importância dos erros e a qualidade da tradução vietnamita do manual de manutenção. Se a qualidade for elevada, existem poucas diferenças entre trabalhadores americanos e vietnamitas. Se a tradução for medíocre, é preferível os vietnamitas utilizarem o manual na sua versão inglesa, apesar de conhecerem mal esse idioma. Se a tradução for má, o resultado é absolutamente catastrófico. Estas diferenças são ainda mais fortes devido à dificuldade do texto técnico. Tendo em conta o preço da tradução efectuada por um especialista, Sinaïko estudou o resultado da tradução efectuada por computador. O resultado apenas pode ser aceite com as traduções automáticas revistas por um especialista. Mais uma vez, estas diferenças são ainda mais fortes devido à maior dificuldade do texto.

\section{I.2 - A análise do trabalho : a chave para a eficiência da organização do trabalho}

7 Experiências laboratoriais, modelos supostamente adequados de uma realidade, por vezes, muito complexa, devem permitir depreender os princípios sobre os quais será fabricado um novo dispositivo técnico. Supor-se-á que este dispositivo irá então induzir na realidade o modo de acção observado experimentalmente. Esta abordagem comportamentalista (behaviorista), muito coerente relativamente à do engenheiro do gabinete de estudos e à do organizador do trabalho tayloriano, constituiu o método essencial da engenharia dos factores humanos abordada no título do livro de Chapanis, 
da psicologia da engenharia de Lomov (URSS), de uma parte importante da ergonomia britânica de Floyd, Murrel e Welford. Continua indispensável em muitos casos mas apenas na medida em que é uma fase entre a análise do trabalho que permite depreender um modelo adequado da realidade do trabalho e o regresso ao real que assegura a validação do modelo.

8 Faverge, um dos fundadores da ergonomia francesa, publicou em 1956 com Ombredane, L'analyse du travail (A análise do trabalho) onde demonstra que os trabalhadores realizam uma actividade por vezes muito diferente da que lhes foi prescrita. Os comportamentos desses operadores correspondem a exigências da tarefa ignoradas pelos criadores (não pode ser consultado um contador mal localizado e é negligenciado a favor de avisos sonoros informais), a condições imprevistas (calor, iluminação, velocidade), a características individuais não previstas (deficiências físicas ou sensoriais, dimensões corporais maiores ou menores do que as de um trabalhador médio).

9 É necessário indicar que a análise do trabalho ergonómico é muito mais aprofundada do que a que se limita à cronometragem dos tempos e movimentos, considerando apenas a acção do trabalhador nos objectos. Para um ergonomista, a análise do trabalho concede um lugar privilegiado à recolha e processamento da informação e restitui, portanto, a dimensão cognitiva que Taylor afirmou negar na actividade operária. Os desenvolvimentos mais recentes da análise do trabalho conferem um estatuto muito importante à análise do discurso espontâneo ou provocado. Podemos, sem dúvida, ver neste movimento uma extensão do behaviorismo: o olhar e a fala são igualmente comportamentos. Na realidade, a análise do trabalho ergonómico não pode ser correctamente realizada sem que o trabalhador individual e colectivo participe não só na recolha dos dados como também na interpretação dos mesmos. A prática da análise do trabalho ergonómico põe um termo à ficção do trabalho prescrito e desvenda a área mental frequentemente tão vasta que separa trabalho real e trabalho prescrito, área essa cujas extensão e natureza variam mais ainda, para uma mesma tecnologia, nos países importadores do que no próprio país de origem.

Os trabalhos dos ergonomistas franceses demonstram que a análise do trabalho é uma condição prévia à melhoria dos distúrbios lombares associados a uma postura incorrecta imposta pela tarefa (Laville, Teiger), à redução dos perigos associados à exposição a produtos tóxicos ou agentes físicos (Wisner), à prevenção dos acidentes do trabalho (Leplat, Cuny), à formação (de Montmollin), ao conhecimento do conteúdo do trabalho e avaliação da qualificação (Guérin, Duraffourg). Além disso, Theureau demonstra a importância da análise das actividades complexas (cuidados hospitalares) em que várias tarefas se combinam de forma irregular.

11 Em muitas situações, uma análise do trabalho, por vezes longa e árdua, resulta na evidenciação de anomalias ocultas da situação de trabalho, facilmente resolvíveis uma vez reconhecidas, graças aos conhecimentos ergonómicos clássicos. Em outros casos, conforme foi visto, terá de ser extraído do real um modelo que retome os pontos críticos, haver uma experimentação em situação real ou em laboratório e validação dos resultados: eis a abordagem ergonómica completa. Finalmente, em muitas outras circunstâncias, descobre-se que os trabalhadores inventaram soluções felizes para dificuldades ignoradas pelos organizadores. A acção ergonómica consiste então em reconhecer esta invenção, facilitá-la tecnicamente e generalizá-la eventualmente (sem prejuízo dos direitos do inventor !). 


\section{II - Determinadas grandes modalidades da transferência de tecnología}

É possível adoptar diversas classificações nas modalidades de transferência de tecnologia para os países em vias de desenvolvimento industrial. Numa primeira abordagem, distinguir-se-á o que é da competência directa e, frequentemente, exclusiva do controlo estrangeiro e diz respeito à ergonomia clássica e à política mundial de organização do trabalho e relações sociais da empresa transnacional responsável. De seguida, ter-se-á em conta as situações em que se constitui ou tende a constituir uma indústria nacional específica de cada país em vias de desenvolvimento industrial.

\section{II.1 - A transferência de tecnologia sob controlo estrangeiro}

13 Quando a transferência de tecnologia é realizada sob a responsabilidade completa, financeira, técnica e social de uma empresa estrangeira pertencente a um país desenvolvido industrialmente (PDI), a negociação das condições de trabalho com as autoridades do país anfitrião é, frequentemente, muito limitada, independentemente de a forma contratual imposta ser a de uma associação com financeiros do país em vias de desenvolvimento industrial (joint-venture). Independentemente do estatuto jurídico, relembra, demasiado frequentemente, o que acontecia nos territórios concedidos. Os resultados desta situação nas condições de trabalho podem ser muito diversificados caso se trate da transferência de desperdícios ou da transferência total (ilhas antropotecnológicas). Aliás, podem ser observadas, simultaneamente, as duas formas extremas de modos de produção no mesmo país em vias de desenvolvimento industrial, em duas partes de um mesmo sistema de produção instalado por uma empresa estrangeira. Não é surpreendente, pois esta diversidade extrema foi descrita em França, há 20 anos, (Mallet, 1964) e corresponde a diferentes representações das necessidades da produção pelos responsáveis industriais.

\section{II.1.1 - A transferência de desperdícios}

14 A transferência de desperdícios diz respeito a empresas onde foram instaladas máquinas de um modelo antigo, já usadas, por vezes perigosas, onde foram utilizados edifícios vetustos ou construídos novos edifícios insuficientes do ponto de vista do volume, condições térmicas e higiénicas, onde nada foi previsto para o transporte, alojamento, alimentação, formação, saúde dos trabalhadores ou onde foram previstas soluções miseráveis: transporte de trabalhadores amontoados por meio de camiões sem lonas, alojamento em dormitórios com beliches e sem instalações sanitárias adequadas, etc. É igualmente nessas empresas que trabalham crianças, que são impostas cadências elevadas, uma disciplina de ferro, uma duração do trabalho excessiva, o trabalho por turnos, a semana de seis ou sete dias. É óbvio que os resultados na saúde dos trabalhadores são desastrosos e que ocorrem muitas perdas do ponto de vista da produção. Contudo, as empresas agrícolas e industriais deste tipo conseguem benefícios devido a salários e encargos sociais baixos e ao tipo de produção seleccionado. 
15 É óbvio que a única solução para este tipo de situação é de natureza política graças a uma boa legislação do trabalho e respectiva aplicação rigorosa. Na verdade, muitos governos toleram essas situações por causa da sua debilidade económica e política ou até mesmo devido ao seu comprometimento para com as empresas estrangeiras. Nestas condições, não são de admirar as revoltas que se produzem todos os anos no mundo e que podem até resultar em revoluções. Entende-se, então, a implicação política, económica e financeira de determinadas condições de trabalho quando a selecção retida consistiu em transferir para um país em vias de desenvolvimento industrial todos os desperdícios que as sociedades industriais rejeitaram : material, organização do trabalho e condições sociais.

\section{II.1.2 - A transferência total}

Entende-se por "transferência total" uma situação praticamente oposta em que, devido à natureza dos fabricos, já não foi transferido o dispositivo de produção antigo mas sim o mais moderno. São, habitualmente, empresas multinacionais que, ao venderem o mesmo produto em todo o mundo, devem obter a mesma qualidade em todos os seus centros de produção, tornando-se então intermutáveis. Para obter esse mesmo produto, a empresa transferiu não só o mesmo dispositivo técnico e as máquinas, como também a organização do trabalho e o dispositivo de formação mais recentes. Todavia, como tal não bastou, a empresa multinacional, seleccionando os seus futuros funcionários segundo critérios rigorosos, fornece aos mesmos alojamentos, meios de transportes e, até mesmo, escolas e hospitais, conforme faziam determinadas empresas europeias dos Séculos 18 e 19 [salina de Arc-et-Senans, chocolataria Menier em Noisel, empresas carboníferas e siderurgias (de Wendel, Schneider)]. É dessa forma que se constituem "ilhas antropotecnológicas" em que é determinado um conjunto tão próximo do do país de origem que até pode ser encontrada a mesma patologia (por exemplo, depressões nervosas na electrónica), mas também as mesmas vantagens (reduzida taxa de acidentes, de rotatividade do pessoal, de absentismo, etc.).

Ainda se fala em ilhas, pois os trabalhadores dessas empresas encontram-se profundamente cortados do estilo de vida dos seus compatriotas, apesar de viverem, geograficamente, no seu próprio país. Esta situação extrema tem a grande vantagem de demonstrar até que ponto a transferência de tecnologia é uma transferência cultural. Pode ser apresentada uma prova em contrário, isto é, as empresas que permanecem no âmbito cultural e social nacional e compram máquinas estrangeiras nem sempre podem, conforme iremos ver mais adiante, realizar as condições de trabalho e normas do país de origem. Não se trata de uma inferioridade específica qualquer, mas sim de um desvio social e cultural que convém analisar e, provavelmente, reduzir.

Pode ser observada uma consequência fundamental do êxito dessas "ilhas antropotecnológicas" nos países mais diversificados: não existem diferenças nas capacidades cognitivas fundamentais dos trabalhadores pertencentes aos diferentes povos e civilizações. Uma investigação recente de Meckassoua (1983) demonstra que um centro-africano que passou toda a sua infância e adolescência numa aldeia, longe de qualquer civilização técnica moderna, pode elaborar uma imagem operacional extremamente complexa se tiver de controlar um dispositivo de produção complicado (cadeia de trasfega de cerveja com rotulagem e colocação em caixas). Esta imagem é suficientemente elaborada para ser objecto, por parte do operador, de um ensino propriamente dito com etapas didácticas progressivas. São factos que não são novos em 
termos fundamentais em neuropsicologia, mas para os quais se adopta, por vezes, um modo de expressão filosófica e até mesmo ideológica. Talvez não seja pior voltar a dar provas disso no campo industrial.

Outra observação interessante na perspectiva analisada é que a constituição dessas ilhas não é, de todo, afectada pela desconfiança universal. São essas fábricas que se pretende mostrar, antes de mais, aos visitantes oficiais na maioria dos países, pois é lá que reside o êxito técnico e humano. Determinados países, em especial na Ásia, optaram há muito por desenvolver ao máximo a transferência total. o paradoxo - ou as condições objectivas - requer que essas grandes ilhas antropotecnológicas sejam... ilhas geográficas.

Singapura é o melhor exemplo disso, devido também ao facto histórico da sua ruptura com a Malásia. Hong-Kong e Taiwan são exemplos menos bons por causa das suas condições sociais mais discutíveis. O próprio Japão é o grande exemplo histórico, embora exista uma grande diferença, ou seja, a excessiva importação da tecnologia e organização do trabalho estrangeiras foi efectuada sob controlo nacional e foi seguida da constituição de uma poderosa produção nacional de tecnologia e modos de organização.

\section{II.2 - A transferência de tecnologia sob controlo nacional}

21 É óbvio que as contribuições ergonómicas abordadas no ponto I.2 e descritas no livro de Chapanis satisfazem bastante bem a transferência de tecnologia sob controlo estrangeiro prevista mais acima. Foram publicadas outras obras excelentes, desde há dez anos, que permitem aprofundar diversos pontos como, por exemplo, o texto de Sen (1981) sobre os edifícios industriais em países tropicais.

22 Em contrapartida, existem poucos dados em relação às grandes dificuldades que cada país em vias de desenvolvimento industrial enfrenta para se industrializar, comprando dispositivos de produção mais ou menos adequados às respectivas necessidades. 0 intuito da antropotecnologia consistiria em contribuir para a elaboração de algumas respostas neste campo específico.

Apesar de existirem muitos exemplos de transferência com êxito, começar-se-á por enumerar os efeitos negativos observados e respectivas consequências, descrevendo, de seguida, as características das diversas modalidades de transferência sucessivamente utilizadas.

\section{II.2.1 - Efeitos negativos da transferência de tecnologia}

É possível distinguir o que afecta a saúde dos trabalhadores e incide na produção.

\section{II.2.1.1 - Os impactos na saúde incidem na higiene industrial, higiene do desenvolvimento e acidentes do trabalho}

Quase todas as actividades industriais possuem os seus próprios riscos tóxicos. Pode acontecer que determinados fabricos particularmente perigosos sejam objecto de uma proibição nos países vendedores, sendo, no entanto, transferidos para um país em vias de desenvolvimento industrial (por exemplo, transferência do processamento do 
minério de ferro do Japão para as Filipinas). Trata-se aqui de uma transferência puramente negativa.

Pode acontecer que produtos sejam pouco perigosos nas condições específicas de utilização do país vendedor, tornando-se devastadores nas situações difíceis do país comprador. Foi assim que o Brasil foi obrigado a proibir a utilização dos insecticidas organomercuriais no tratamento das plantações de cana-de-açúcar após uma epidemia de lesões neurológicas sofrida pelos trabalhadores de cana-de-açúcar no norte do Estado do Rio de Janeiro (Chuairi da Silva \& Maluf, 1980). Tratava-se de uma transferência de tecnologia favorável para a produção e desastrosa para a saúde.

Finalmente, determinados cancros profissionais desenvolvem-se mais amplamente nas populações com determinados caracteres genéticos e habituadas a determinados tipos de alimentos (cancro da rinofaringe dos chineses de Cantão, cancro do fígado dos trabalhadores senegaleses do amendoim devido à aflatoxina produzida pelo bolor dessas sementes e grande frequência da hepatite B entre eles).

Entende-se por "doenças do desenvolvimento" diversas afecções que surgem ou aumentam significativamente aquando da transferência de tecnologia. É conhecido o aumento significativo das parasitoses nas áreas irrigadas após a construção de uma barragem em países tropicais (Assuã no Egipto, Bandama na Costa do Marfim). A combinação dessas parasitoses com uma alimentação insuficiente e as gravidezes pode resultar numa redução significativa da capacidade de trabalho devido à deficiência de ferro sanguíneo para a síntese da hemoglobina (colhedoras de chá no Sri Lanka estudadas por Baker e Demayer, 1978). É óbvio que as barragens, devido à sua acção maciça sobre a ecologia, são uma das formas de transferência de tecnologia a exigir, de forma mais clara, estudos prévios multidisciplinares próximos da antropotecnologia.

29 Foi igualmente demonstrada a importância dos problemas de higiene mental nas aglomerações miseráveis que servem de alojamento para muitos trabalhadores industriais dos países em vias de desenvolvimento industrial. Excessiva duração do dia de trabalho e trajectos, promiscuidade, falta de sono e choque cultural reúnem-se para favorecer grandes síndromas psiquiátricos ou, mais frequentemente, síndromas depressivos marcados por actos agressivos direccionados para os outros ou para si (suicídios ou comportamentos suicidas).

30 Finalmente, a segurança do trabalho é, frequentemente, desfavorável no caso de transferência de tecnologia, em especial nas minas, construção e obras públicas em que podem ser observadas taxas de acidentes duas a três vezes superiores às dos países desenvolvidos industrialmente. As causas dos acidentes são múltiplas: situações de coactividade com pessoal em demasia e mal formado, controlo insuficiente em quantidade e qualidade, dificuldades de comunicação (manuais de instruções redigidos num idioma estrangeiro, chefia que conhece mal o idioma dos trabalhadores), manutenção incorrecta e utilização inadequada do material (estudo sobre a utilização e manutenção das escoras hidráulicas nas minas de fosfato tunisianas, Sahbi, 1983).

\section{II.2.1.2 Os erros de cálculos da produção}

31 Os erros de cálculos da produção são igualmente importantes não só por motivos directos associados ao êxito económico da empresa, como também de forma indirecta devido às dificuldades sociais consecutivas (redução dos salários, das vantagens sociais e dos investimentos que criam empregos ou melhoram a produtividade). 

das máquinas que pode passar abaixo dos $50 \%$ em determinados sectores-chave, por exemplo, na Índia (Krishna, 1980). A própria interrupção das máquinas pode estar associada a diversas categorias de causas : más condições climatéricas, manutenção insuficiente e indisponibilidade de peças sobresselentes, absentismo e rotatividade do pessoal devido a más condições de trabalho e vida. No entanto, essas considerações não devem ser generalizadas sem precauções. Assim, a produtividade é mais elevada na fábrica Renault de Valladolid em Espanha do que na fábrica-mãe da região parisiense. De facto, a Espanha é um país desenvolvido industrialmente e são trabalhadores espanhóis com uma formação geral e técnica de elevado nível que trabalham em Espanha enquanto, em França, são principalmente trabalhadores emigrantes que se encontram numa situação semelhante à da transferência de tecnologia, à da transferência de população. Relembrar-se-á igualmente que nos países desenvolvidos industrialmente, determinados sectores recentes possuem uma taxa de compromisso das máquinas muito fraca : novas oficinas robotizadas, centro de reprocessamento dos combustíveis nucleares [10 \% da capacidade máxima da fábrica de La Hague (França) e 15 \% para a fábrica Tokaï Mura (Japão) devido à multiplicidade dos acidentes].

A qualidade insuficiente da produção está igualmente associada a um material inadequado, manutenção insuficiente, ausência de determinados produtos, deficiência do material de controlo, formação medíocre ou nula do pessoal, más condições de trabalho e vida. Os resultados são, portanto, a impossibilidade de exportar e a necessidade de proteger artificialmente o mercado nacional dos fabricos estrangeiros de melhor qualidade.

Entende-se assim que as condições de trabalho e vida aceitáveis são, simultaneamente, a condição e o resultado de uma realização correcta da transferência de tecnologia.

\section{II.2.2 - As dimensões da transferência}

Os dirigentes da maioria dos países em vias de desenvolvimento industrial estão perfeitamente cientes dos eventuais efeitos negativos da transferência de tecnologia, embora continuem a considerar indispensável a industrialização do respectivo país. Não iremos discutir aqui a pertinência desta posição associada ao crescimento demográfico, aos limites do aumento da produção agrícola ou a uma vontade de independência. Considerar-se-á a própria selecção do tipo de indústria a promover como um facto anterior à nossa intervenção mas poder-se-á reflectir sobre duas dimensões da transferência : a sua amplitude e o seu grau de realização.

\section{II.2.2.1 - A amplitude da transferência é um tema frequentemente abordado.}

Numa primeira etapa, os industriais dos países em vias de desenvolvimento industrial importam máquinas isoladas, apercebendo-se, rapidamente, de que para realizar fabricos completos, é extremamente difícil e dispendioso utilizar máquinas pouco compatíveis ou até incompatíveis entre elas, caso frequente se forem oriundas de fornecedores diferentes. Sahbi (1983) demonstra, por exemplo, que a oficina alemã de 
reparação de escoras comprada pela Compagnie des Phosphores não se adequa às escoras importadas de França. na mão" em que a qualidade e quantidade da produção são garantidas pelo vendedor que irá fornecer não só o material, como também a organização do trabalho, os processos de direcção e controlo da empresa (gestão), a formação dos trabalhadores, funcionários e quadros. Esta garantia irá, por vezes, resultar na permanência prolongada dos quadros e técnicos "expatriados", resultando praticamente na associação duradoura do país comprador com uma empresa multinacional ou transnacional, privada ou pública. A lógica da transferência consiste em resultar na transferência extensiva que, conforme vimos, cria ilhas que até podem não ser prósperas e que, de qualquer das formas, não alteram o país e permanecem independentes do mesmo. Em relação a isso, pode-se insistir sobre o facto de qualquer máquina ser cultural, pois traduz o que o engenheiro e o desenhador possuem como representação da técnica, economia, empresa e trabalhadores. Assim, esta máquina é uma forma de atrair outras máquinas análogas e uma organização que corresponda às mesmas.

A extensão da transferência tem limites inelutáveis quando um país possui apenas um desenvolvimento industrial limitado e resulta no aparecimento de isolamentos. Tendese, demasiado frequentemente, a subestimar, devido ao êxito e à produtividade das grandes empresas de países desenvolvidos industrialmente, a importância do tecido industrial que as rodeia, as múltiplas pequenas e médias empresas que fornecem o material especializado e, mais ainda, o pessoal altamente qualificado indispensável no caso de dificuldades, a disponibilidade das antenas de fornecedores de aparelhos de medição, regulação e controlo, a celeridade aquando da entrega das peças sobresselentes. Uma avaria resolvida em Paris em duas ou três horas pode demorar dois ou três dias numa cidade provincial francesa, duas a três semanas em África do Norte, dois ou três meses em África Subsaariana, devido às diferenças de densidade do tecido industrial. Foram elaborados dois tipos de soluções para evitar este tipo de dificuldades : a constituição de grandes parques de peças sobresselentes (até dez vezes mais importantes em países em vias de desenvolvimento industrial do que em países desenvolvidos industrialmente) e a organização de serviços de manutenção consideráveis na empresa ou, então, a criação perto da empresa de uma filial da empresa vendedora que gere um contrato de manutenção exclusivo da instalação vendida. Em ambos os casos, a despesa é extremamente elevada e pesa nos preços de custo. $O$ peso torna-se ainda mais importante por a instalação ser complexa e frágil.

\section{II.2.2.2 - O grau de realização da transferência é uma dimensão capital.}

41 A sua insuficiência está frequentemente na origem de dificuldades, por se tratar de um erro inicial, uma restrição do contrato ou más comunicações entre vendedor e comprador. 

correspondem a uma retenção cada vez mais forte do conhecimento pelos fornecedores. O primeiro dispositivo, electromecânico, foi facilmente dominado pelo pessoal filipino e puderam ser fabricadas peças sobresselentes no local. O dispositivo electrónico que foi comprado posteriormente era de compreensão e reparação mais difíceis. No entanto, o domínio do sistema foi progressivamente adquirido pelo pessoal da empresa de telefones filipinos, embora todas as peças sobresselentes tivessem de ser compradas à empresa vendedora. 0 dispositivo informático foi intelectualmente muito bem dominado pelos excelentes informáticos filipinos, mas estes não podem tratar da manutenção e reparação por estas terem sido integralmente atribuídas a uma filial do vendedor, o contrato não os autorizando igualmente a modificar o software, apesar de este, concebido por um país europeu continental, não se adequar de todo a um arquipélago sujeito a tufões do Pacífico. permanente de técnicos estrangeiros a ocuparem cargos-chave do conhecimento tecnológico, inclusive em países que possuam engenheiros e técnicos de elevado nível em quantidade suficiente. São transferências inacabadas por retenção do conhecimento.

Os erros iniciais são muito frequentes e devem-se, principalmente, ao facto de o vendedor não conhecer a realidade do país comprador e o comprador não conhecer a origem complexa do êxito da tecnologia em causa no país vendedor. exemplo, os restritos limites térmicos do bom funcionamento, as reduzidas tolerâncias de flutuação da tensão eléctrica, as exigências de qualidade da água ou de um ou outro aprovisionamento. De forma ainda mais subtil, subestimar-se-á as inter-relações dos projecto. Por exemplo, numa fábrica de produção de bicicletas, as autoridades vietnamitas tinham pensado utilizar melhor os créditos franceses e incluir apenas na fábrica entregue as fases de fabrico cuja tecnologia não dominavam, sendo o resto fabricado pelos próprios. Assim, obteve-se uma linha de produção rompida espacialmente em diversos pontos, exigindo armazenamentos importantes e favorecendo a corrosão num clima quente e húmido.

do construtor permitir uma manutenção e desenvolvimento muito eficientes. De facto, é um meio poderoso para o vendedor conseguir benefícios e manter o seu controlo fornecimento obrigatório de peças sobresselentes, por vezes, sem qualquer relação com as exigências da exploração local, contratos de manutenção dispendiosos, software informático de elevado preço e utilização discutível.

A má qualidade das comunicações entre vendedores e compradores é uma questão importante e sobre a qual é possível uma acção antropotecnológica.

O principal aspecto que pode ser destacado com Sinaïko (1975) é o da linguística dos textos escritos. Relembra-se a relação estreita que demonstrou existir entre a qualidade da tradução das instruções e o nível da manutenção. Quantas máquinas são vendidas com indicadores, inscrições, manuais de instruções escritos num idioma desconhecido ou após uma péssima tradução? 
São alegados dois grandes motivos: um prende-se com o facto de os trabalhadores, respectivos superiores ou, pelo menos, os formadores conhecerem o idioma do país vendedor. Trata-se, habitualmente, de um erro quando considerada a profunda compreensão dos dados técnicos. Devemos parar de considerar que existem uma África francófona e outra anglófona, que toda a América a sul do Rio Grande é hispanófona ou lusófona e que a Ásia do Sul e a do Sudeste são anglófonas. Trata-se, em muitos casos, de um conhecimento muito superficial dos grandes idiomas veiculares, enquanto os trabalhadores e muitas outras pessoas na empresa continuam a raciocinar num idioma vernacular e apenas entendem bem o mesmo.

O outro motivo, muito mais sério, é que as traduções são dispendiosas. No entanto, será que este motivo financeiro deve ser retido ? Recentemente, uma grande empresa de um país desenvolvido industrialmente vendeu a um país em vias de desenvolvimento industrial um conjunto de motores a diesel de várias centenas de milhões de francos. Uma boa tradução de 40 páginas do manual de utilização é fornecida aos compradores no seu idioma veicular, o português (de Godoy Garcia, 1982). Mas o manual de manutenção é composto por várias centenas de páginas e não está traduzido, o que corresponde a uma poupança de alguns milhares de francos, no máximo, num mercado mil vezes mais importante.

Ora, sabe-se que as consequências da ignorância assim favorecida podem ser consideráveis na produtividade e segurança. É certo, no entanto, que os problemas linguísticos são, frequentemente, complexos: existem argelinos berberófonos que percebem melhor o francês do que o árabe e filipinos que conhecem melhor o inglês do que o tagalo. Os indianos mantiveram o inglês como idioma oficial porque o hindi é apenas o idioma vernacular mais importante, inaceitável para muitos cidadãos que falam bengalês, tâmil ou urdu. Podem ser efectuadas observações análogas em relação às representações figuradas. Wyndham e Sinaïko dão, no livro de Chapanis, exemplos de mal-entendidos gráficos e retomam os trabalhos de Hudson neste campo.

a surgir, naturalmente, o problema do idioma no campo da formação oral Surgem aqui, pelo menos, duas perguntas. É, sem dúvida, muito mais difícil encontrar determinado número de formadores que conheçam, simultaneamente, a tecnologia e o idioma vernacular do que um único bom tradutor.

3 Uma tradução de boa qualidade é, de qualquer das formas, uma excelente base para os formadores estrangeiros e autóctones. Uma questão muito mais grave prende-se com a natureza do ensino, pois incide no próprio sentido da transferência. Sabe-se que existe, por um lado, o trabalho prescrito, imaginado nos gabinetes dos métodos, expresso nos manuais de instruções e, portanto, escrito numa linguagem científica, e, por outro lado, o trabalho real, o que permite ao dispositivo funcionar (por vezes, de forma discutível), elaborado e transmitido entre trabalhadores no seu próprio idioma com um vocabulário, frequentemente, inventado pelos mesmos. 0 que deve ser transferido : o trabalho prescrito marcado pela cultura dos engenheiros do país vendedor e respectiva visão abstracta do sistema ou o trabalho real marcado pela cultura operária do país vendedor... ou ainda pela dos trabalhadores estrangeiros a que este país recorre ? Sabese que determinados países vendedores mandam, cada vez mais, trabalhadores com experiência para os países compradores quando um sistema complexo avaria. 


\section{III - Esboço da antropotecnologia}

54 A industrialização dos países em vias de desenvolvimento industrial e o seu aspecto mais crítico, a transferência de tecnologia, provocam, conforme vimos, muitas dificuldades, independentemente de não serem tratadas as questões fundamentais do desenvolvimento.

Muitas questões surgem em todos os casos de transferência, embora com uma grande diversidade em termos de importância de um país para outro. A análise desta unidade e diversidade é o âmago da antropotecnologia. Os resultados desta análise podem ser utilizados de duas formas : por um lado, para fornecer aos vendedores e compradores meios de reflexão sobre as respectivas estratégias económicas, políticas e ideológicas, e, por outro lado, para as transferências terem êxito graças a uma metodologia adaptada a cada etapa da operação.

\section{III.1 - Campo da antropotecnologia : unidade e diversidade das situações de transferência}

Para especificar a amplitude do campo da antropotecnologia, é necessário explicar, antes de mais, as noções de desenvolvimento industrial e transferência de tecnologia.

\section{III.1.1 - Os países em vias de desenvolvimento industrial}

O agrupamento de uma centena de países, marcados por uma diversidade geográfica, histórica, económica e um vocábulo geral, pode ter efeitos interessantes do ponto de vista político, mas não resulta em qualquer explicação da diversidade das trajectórias de cada país. A própria noção de "país em vias de desenvolvimento" é das mais discutíveis. É preferível a noção de "País em Vias de Desenvolvimento Industrial" utilizada neste texto.

De facto, entre as nações com uma indústria ainda reduzida, podem ser encontrados países como a China, a Índia, o Egipto ou a Grécia, países cuja cultura antiga nos deu, no passado, as próprias bases da nossa civilização técnica e administrativa. Deve ser relembrado que, há 200 anos, tentava-se surpreender os processos técnicos da porcelana chinesa e do fabrico das cotonnades indianas que, desde então, se tornaram num elemento importante do vestuário "tradicional" de determinadas províncias francesas. No início do século, os pobres trabalhadores estrangeiros analfabetos a que Taylor se dirigia eram neerlandeses ou suecos. As mudanças rápidas que surpreendem os europeus e os americanos e que se produzem em determinados países da Ásia não são assim tão surpreendentes quando conhecida a sua história. Lévi-Strauss relembrava, recentemente (1980), o elevado nível da administração e cultura japonesas no Século 16, a existência, no Século 18, de empresas industriais e financeiras japonesas, das quais algumas se tornaram em grandes grupos económicos do país. Um cartaz afixado no aeroporto de Seul por uma companhia coreana resume de forma directa estas considerações de antropologia cultural histórica: "Construímos o primeiro observatório celeste em pedra, o primeiro navio couraçado em ferro, a primeira tipografia. Podemos ser, hoje, os melhores em termos de construção electrónica". É claro que nem tudo pode ser explicado recorrendo ao passado; a 
vontade política e económica, bem como a descoberta de riquezas naturais contribuem muito, mas ainda mais com base num substrato favorável e judiciosamente utilizado.

Da mesma forma, subestimou-se muito, nos últimos cinquenta anos, a originalidade de cada um dos países industriais e respectiva dinâmica. 0 sinal mais evidente desta forma de ver prende-se com a classificação de todos os países do mundo numa mesma escala em função dos diversos índices de industrialização, em especial do PNB por habitante ; os países com melhor classificação nesta escala são, então, propostos como modelos. Assim, foi recomendado sucessivamente aos dirigentes industriais franceses adoptar o modelo americano em 1955, o modelo oeste-alemão em 1965 e o modelo japonês em 1975, mas sem qualquer êxito. Da mesma forma, é proposto o modelo de Hong-Kong, Taiwan, Singapura ou Japão na Ásia do Sul ou Sudeste, sem que o resultado seja muito convincente.

Pode depreender-se destas considerações a ideia segundo a qual o desenvolvimento industrial de cada país deve ser considerado em si e por si à luz de um conhecimento internacional que a antropotecnologia pode contribuir a constituir.

61 A diversidade dos países em vias de desenvolvimento industrial surge nitidamente quando determinados países, ainda muito pobres do ponto de vista do nível de vida da maioria dos seus habitantes, se tornam, simultaneamente, exportadores de produtos de alta tecnologia (Brasil, Coreia do Sul, Índia, México, etc.). Sabe-se que Mc Namara, Director do Banco Mundial, distingue estes países dos outros países em vias de desenvolvimento industrial, recorrendo ao nome "Advanced Developing Countries" (Países em Desenvolvimento Avançados). O primeiro número dos cadernos IREP/ Développement (Courlet, Français \& Judet, 1981) foi dedicado aos mesmos com o título "la semi-industrialisation" (a semi-industrialização). Foi relembrado, mais acima neste texto, que é nesses países que existe uma actividade ergonómica importante.

\section{III.1.2 - A transferência de tecnologia}

62 A transferência de tecnologia é, demasiado frequentemente, considerada na literatura francófona como estando orientada para os países em vias de desenvolvimento industrial mais afastados do sistema industrial, sendo o caso da maioria dos países de África Subsaariana. $\mathrm{Na}$ realidade, a transferência de tecnologia é um poderoso fenómeno histórico e teimamos, actualmente, em observar uma fase específica através de modelos teóricos, simultaneamente, demasiado restritos e demasiado gerais.

63 Pode ser utilizado como exemplo histórico de efeitos maciços a transferência da hévea do Brasil para a Malásia, realizada pelos britânicos há 100 anos, transferência essa que determinou a ruína de uma parte do Brasil (Manaus), a migração maciça de chineses na Malásia, criando um grave problema racial nesse país e resultando, consequentemente, na independência posterior de Singapura de população maioritariamente chinesa.

Conforme iremos ver, a transferência de tecnologia provoca uma série de problemas semelhantes, independentemente dos países exportadores e importadores, mas provoca problemas específicos quando a estrutura industrial do país de acolhimento é demasiado fraca para controlar a tecnologia transferida. Deve ser realizada uma transferência activa e o papel da antropotecnologia consistiria em permitir uma reflexão sistemática sobre estas condições. Pode ser considerada crucial a realização dos estudos comparados de transferência, quer em paralelo (diversidade de êxito das transferências de técnicas francesas consoante os países), quer em série (transferência 
de um computador americano para França, de uma fábrica de montagem francesa para o Brasil, de uma oficina de tecelagem brasileira para Angola). Em todos os casos, surgem, por um lado, o choque de modernização mais ou menos piorado por erros e, por outro lado, fenómenos específicos. Não se deve pensar que as trocas sul/sul actualmente recomendadas evitam esse duplo efeito, conforme demonstrado por uma reflexão recente sobre as transferências do Brasil para Angola (Abrahão, 1983).

Para ilustrar estas observações sobre os efeitos da transferência, descrever-se-á rapidamente uma situação norte/norte e ver-se-á que grande parte dos fenómenos pode ser encontrada em outras situações de transferência. De facto, quando uma empresa francesa deve adquirir um computador para os seus serviços administrativos ou técnicos, a constatação inicial é que, frequentemente, deve ser comprado um sistema informático americano. A primeira avaliação está associada ao preço do próprio computador (hard) mas, mais cedo ou mais tarde (por vezes, demasiado tarde para o seu equilíbrio financeiro), a empresa vai descobrir outras despesas importantes e absolutamente necessárias: programas por vezes muito dispendiosos (soft), locais climatizados indispensáveis para o computador, contrato de manutenção muito caro, salário elevado dos técnicos de informática, necessidade de uma formação vasta e aprofundada do pessoal dos diversos serviços relacionados com o computador.

Por vezes, as coisas ainda correm menos bem : devido à falta de uma avaliação precisa das necessidades ou à falta de honestidade por parte do vendedor, o computador não se adequa, é demasiado grande ou demasiado pequeno, necessita de complementos dispendiosos ou, então, não é compatível com os elementos de um outro sistema informático com o qual deve comunicar. Este conjunto de dificuldades pode resultar no dobro ou triplo das despesas previstas no orçamento inicial rapidamente adoptado e levar a empresa a não ser bem-sucedida. Devido a esses imprevistos, assiste-se, demasiado frequentemente, a medidas económicas brutais que incidem, praticamente sempre, no pessoal. São conhecidas as medidas, por vezes, brutais e excessivas de despedimento que acompanham a mudança de tecnologia e as exigências, por vezes, demasiado fortes em relação à densidade do trabalho por computador. Estas decisões apenas pioram, frequentemente, a situação financeira, pois as próprias preocupações relativas ao emprego e más condições de trabalho resultam em problemas sérios, avarias e erros graves. Podemos ter uma ideia da extensão dessas perturbações se soubermos que, recentemente, o governo dos Estados Unidos considerava que uma eventual redução em $1 \%$ dos erros informáticos dos seus serviços iria representar uma poupança de 25 milhões de dólares por ano.

Na sequência dessas dificuldades repetidas, determinadas empresas entregam agora a consultores independentes dos grandes construtores de computadores a previsão técnica e a avaliação financeira da engenharia da futura informatização. Vislumbram-se assim aqueles que poderiam ser, em outras condições, especialistas antropotecnológicos.

Foi visto mais acima que os efeitos da transferência de tecnologia na sociedade e o êxito da transferência são, mais ou menos, satisfatórios em função da estrutura industrial do acolhimento. Mais uma vez, não é necessário sair de França para observar os efeitos intensos no plano económico, social e cultural da transferência técnica maciça ocorrida nas aldeias francesas há 30 anos. É nestes termos muito próximos dos marfinenses, mexicanos ou filipinos, que os bretões, bascos e córsicos falam da sua perda de 
identidade, das suas dívidas esmagadoras, bem como do aumento indiscutível do seu nível de vida.

\section{III.1.3 - Orientação e conteúdo da antropotecnologia}

69 Como a ergonomia, a antropotecnologia deveria ser uma arte técnica que permita obter os resultados económicos esperados da transferência de tecnologia, possibilitando, simultaneamente, condições de trabalho e vida satisfatórias para os trabalhadores. Trata-se de um objectivo modesto, sujeito às decisões políticas nacionais e à situação da economia mundial. Também não se trata de uma forma actual de busca da "felicidade", mas sim da saúde.

70 É verdade que essa proposta não é sedutora para os especialistas das ciências humanas habituados a uma descrição crítica dos fenómenos à luz de diversos modelos teóricos. Tivemos de enfrentar a ofensiva dos que afirmam procurar "o verídico", em relação aos que consideram estar apenas "interessados no bem". Para nós, trata-se de uma dicotomia sem significado, não existe qualquer bem social e económico que não assente no verídico, ou seja, no conhecimento científico. Da mesma forma que excelentes físicos ou químicos se expressam na actividade do engenheiro, os especialistas das ciências do homem podem expressar-se na antropotecnologia. Todavia, a experiência da ergonomia ensinou que não basta aplicar a projectos técnicos o conhecimento adquirido em bases críticas. $\mathrm{Na}$ antropotecnologia, deve ser constituído um corpo de conhecimentos com base em investigações especificamente orientadas para a elaboração de soluções. Estes tipos de trabalhos enriquecem naturalmente o conjunto da disciplina, conforme observado no campo da psicologia após o aparecimento da problemática ergonómica.

71 As disciplinas em causa são, sem dúvida, múltiplas, mais numerosas do que a economia e a sociologia que forneceram, até aqui, o essencial das investigações pertencentes ao campo antropotecnológico. Notar-se-á igualmente que, até nestas disciplinas, existe uma forte reivindicação de análise específica de cada país. Não é um mero acaso o marxismo ter conhecido, a par do seu maciço desenvolvimento na URSS, uma expressão muito diferente na China, Itália ou América Latina e surgirem preocupações semelhantes em diversas partes de África (Miske, 1981).

o que surge como sendo essencial prende-se com as características próprias de cada país ou região, começando pela geografia física, climatérica e humana. A convergência de autores tão opostos ideologicamente como Gourou (1982) e Lacoste (1982) não deixa de ser surpreendente, quando reivindicam para a geografia um papel activo na acção de desenvolvimento. A história - ou o seu equivalente para os povos sem qualquer forma escrita ou cujos textos escritos desapareceram - é outra dimensão à qual não pôde escapar este texto, algo que nem procurou fazer. Trata-se, obviamente, de encontrar na história de cada povo os elementos positivos e negativos que permitem compreender a situação actual, não com base numa história universal qualquer, mas sim com base numa história própria, local, nas suas inter-relações com os outros países.

Infelizmente, em muitos casos, o período colonial relativamente recente e respectiva continuação oculta, em determinados casos, os acontecimentos anteriores, por vezes, muito importantes. Por exemplo, a história dos países do Magrebe é muito diversificada há vários milénios e este passado antigo condiciona o futuro, à imagem dos períodos 
coloniais de tipos e durações muito diversificados (Argélia 130 anos, Tunísia 75 anos, Marrocos 44 anos e Líbia 33 anos).

Independentemente dos países estudados com vista a uma transferência de tecnologia, deparamo-nos com a reivindicação de uma identidade nacional, de uma via própria que seria oriunda da geografia e história através de uma cultura e graças a expressões linguísticas de diversos tipos. Foi o motivo pelo qual propusemos o termo antropotecnologia. Tendo em conta a diversidade das abordagens antropotecnológicas, mas a raridade das que consideram a passagem de uma cultura antiga para a industrialização, poderá ser algo um tanto temerário. Pode parecer estranho pedir aos investigadores que se dedicaram à descrição de uma civilização ameaçada pela industrialização para darem recomendações com vista ao êxito de uma transferência de tecnologia, cujo êxito irá apagar mais rapidamente o passado. Na verdade, autores importantes, como Godelier (1982), seguiram esta orientação. Podemos citar o interessante trabalho de Amado (1982) que, especializado na civilização indiana, se interessa actualmente pela forma como as aldeias indianas modificam o seu modo de vida após a introdução de bombas de água que utilizam a energia de células fotoeléctricas. Demonstra as perturbações inesperadas que incidem no sistema de poder económico, na vida das mulheres, dos adolescentes, etc.

Parece que a linguística se encontra nas disciplinas científicas cuja contribuição poderia ser de fundamental importância, na medida em que as estruturas da linguagem reproduzem e induzem as da vida social. Como é possível um dispositivo técnico se tornar numa parte da vida de um grupo humano se este não dispõe da linguagem desta nova actividade, na continuidade da sua linguagem geral? Vimos mais acima a importância de uma tradução correcta e extensa dos manuais de instruções para a utilização dos dispositivos técnicos transferidos.

\section{III.2 - A antropotecnologia nos conflitos económicos, políticos e ideológicos}

76 O discurso relativamente uniforme que acaba de ser apresentado sobre a antropotecnologia parece negligenciar a força das contradições que existem entre países vendedores e compradores de tecnologia, a violência da concorrência entre exportadores e, por vezes, importadores. Também foi deixado de lado o facto de, em muitos casos, um país comprador ter pouca liberdade em termos de selecções. Sabe-se que muitas ajudas incluídas num pacto bilateral são, na realidade, um subsídio concedido a uma empresa deficitária do país exportador. Estas realidades são indubitáveis e são objecto de muitos trabalhos fora do âmbito da antropotecnologia, pois esta supõe as grandes selecções já realizadas e apenas procura que as mesmas tenham êxito. Todavia, esta vontade de limitação apenas faz sentido numa perspectiva de eficiência, o que exige lucidez sobre os grandes conflitos entre os quais as transferências são realizadas. A análise da situação pode levar o antropotecnólogo a afastar-se na eventualidade de, por exemplo, não sentir qualquer interesse pela instalação de uma fábrica de bombas nucleares.

77 Relativamente a isso, podemos relembrar uma declaração de Lacoste que afirmava que "a geografia serve, antes de mais, para estar em guerra". Os nossos melhores mapas não são os "mapas de Estado-Maior"? Como não interpretar no mesmo sentido as 
ocultações ou inversões de placas de sinalização rodoviária pelos nossos regionalistas ameaçados pelas invasões turísticas?

Ainda no campo político, sabe-se até que ponto a transferência de tecnologia pode criar um condicionalismo internacional duradouro: basta relembrar as dificuldades enfrentadas pela China, após a ruptura com a URSS, quando a sua frota de camiões ficou, brutalmente, sem peças sobresselentes ou ainda o recente episódio do fornecimento de tecnologia patenteada nos EUA para a construção do gasoduto siberiano.

Parece inútil relembrar o extraordinário poder político das empresas multinacionais na vida das nações. Esta análise foi efectuada por muitos autores de forma convincente.

É provavelmente no plano ideológico que a ambiguidade do estatuto da transferência de tecnologia coloca as questões de maior gravidade à antropotecnologia. De facto, em quase todos os países em vias de desenvolvimento industrial, as críticas em relação à antropotecnologia partem de três campos.

Para os membros do campo liberal, é necessário realizar a industrialização, custe o que custar. "Poluam-nos" : eis o que foi dito, em tom de brincadeira, por um chefe de estado africano que tentava, a todo o custo, favorecer a instalação de indústrias no seu país. Para os liberais, as ilhas antropotecnológicas são excelentes e o seu maior desejo é que estas se tornem rapidamente num arquipélago. Os liberais podem condenar determinados costumes antigos, o sofrimento dos trabalhadores e respectivas famílias, mas consideram que é o preço a pagar para obter um aumento significativo do nível de vida de uma população em crescimento. Alguns deles até pensam que a cultura nacional não irá desaparecer mas irá, sim, reaparecer sob uma forma moderna, conforme ocorreu no Japão, por exemplo.

Outro campo é o dos culturalistas para quem as estruturas antigas da sociedade e a ecologia do país são bens essenciais, preferindo rejeitar, ao máximo, as importações de tecnologia que perturbaram situações antigas. Estas posições são veementemente expressas nos países que enfrentaram uma excessiva ofensiva por parte dos liberais como no Irão ou Filipinas. A expressão dos culturalistas está, muito frequentemente, associada à das forças religiosas. É, por exemplo, o fundo do excelente livrinho de Miské, intitulado Lettre ouverte aux élites du tiers-monde (Carta aberta às elites do Terceiro Mundo), onde se exprime a convicção segundo a qual o desenvolvimento apenas pode ser alcançado através do regresso à Shura islâmica. Na realidade, os culturalistas também praticam a transferência de tecnologia para evitar o colapso económico, político e até mesmo militar do seu país.

Para os marxistas, a transferência de tecnologia é inevitável, pois é indispensável para permitir a industrialização. Esta não só não irá evitar atingir a sociedade antiga como também será, por vezes, utilizada como ferramenta para destruir o passado. É muito interessante compreender o pensamento na origem de Nova Huta, a cidade siderúrgica polaca, cidade moderna, sem igrejas, edificada em frente à antiga Cracóvia, metrópole histórica e religiosa. É ainda mais interessante observar a irrupção posterior desta tradição no centro da nova cidade.

o esforço máximo realizado neste sentido foi, provavelmente, o da revolução cultural chinesa, pensada de forma claríssima por Mao Tsé-Tung com vista a iluminar o caminho dos países em vias de desenvolvimento industrial, com a China na primeira fila. 
$85 \mathrm{Na}$ maior parte dos casos, a transferência de tecnologia nos países socialistas ganhou uma forma muito mais banal, algo muito semelhante ao que acontece nos países de economia liberal. Sabe-se que, no âmbito da economia centralizada, nem sempre foi possível evitar os problemas de endividamento e sujeição ao estrangeiro, os da divisão internacional do trabalho e, principalmente, da produtividade.

Assim, a antropotecnologia encontra-se em conflitos não só comerciais e económicos, como também políticos e ideológicos. Estes conflitos não são apenas abstractos, matam e fazem sofrer muitos trabalhadores nos países em vias de desenvolvimento industrial, saindo, por vezes, o tiro pela culatra e atingido os países desenvolvidos industrialmente. No entanto, não parece constituir um obstáculo mas sim uma forma de incentivo para um sério trabalho técnico de melhoria da qualidade da transferência.

\section{III.3 - Metodologia antropotecnológica}

87 Em qualquer actividade prática do tipo profissional, a metodologia geral é raramente respeitada na íntegra, tendo em conta as condições da participação ou intervenção. Por vezes, devem ser previstos complementos importantes ou negligenciadas partes inteiras, tendo em conta a experiência anterior dos membros da equipa, experiência essa que incide na transferência de tecnologia em geral, nas características das técnicas a transferir, nas indústrias dos países vendedor e comprador. É óbvio que seria interessante conhecer o melhor possível as características políticas, económicas e comerciais do projecto. Nem sempre é possível.

88 No que respeita à equipa de intervenção, é incontestável que uma sólida participação do país comprador é muito útil. Torna-se cada vez mais possível devido ao crescimento das competências em muitos países.

89 É interessante poder contar também com especialistas do país vendedor, pois conhecem os recursos e inconvenientes das técnicas seleccionadas.

90 Distinguir-se-á, na metodologia antropotecnológica, o estudo prévio e a participação em cada etapa da transferência.

\section{III.3.1 - 0 estudo prévio}

Devem ser reunidas duas categorias de elementos, uns relacionados com o local da transferência e outros com a tecnologia.

92 A abordagem das condições locais específicas pode ser efectuada através da documentação, consulta de especialistas e visita no local.

A documentação é, por vezes, considerável, mas difícil de reunir. Os dados geográficos e antropotecnológicos são, por vezes, obtidos junto de institutos especializados dos países desenvolvidos industrialmente (institutos meteorológicos, institutos geográficos, etc.). O mesmo se aplica no caso dos conhecimentos de ordem patológica ou nutricional ; todavia, os gabinetes regionais das agências das Nações Unidas podem ser muito úteis (OMS, FAO, UNICEF, BIT, etc.).

94 A documentação que existe localmente torna-se, todos os anos, mais consequente devido ao desenvolvimento em todo o mundo de centros de investigação universitários ou governamentais importantes. A visita desses centros e o contacto directo com os 
investigadores irão permitir adquirir os dados concretos que nem sempre são publicados ou que não pertencem, necessariamente, à literatura científica mundial.

A visita da localização da futura fábrica é, por fim, particularmente necessária, pois os especialistas podem descobrir elementos muito importantes, negligenciados pelas primeiras missões compostas, essencialmente, por engenheiros e comerciantes. Notarse-á nas redondezas um pântano cuja drenagem é indispensável se quiser ser evitado um paludismo endémico, a proximidade de um bairro de lata onde iriam morar os trabalhadores da fábrica na eventualidade de não serem construídos alojamentos adequados, a presença de um deserto de areia que o vento poderá levantar em direcção à fábrica, tornando assim a ventilação natural difícil.

O estudo da tecnologia a ser transferida pode ser efectuado de acordo com os métodos habituais de análise do trabalho, de manutenção com o órgão de controlo e os trabalhadores, de consulta dos documentos (absentismo e rotatividade do pessoal, acidentes e incidentes, qualidade e quantidade da produção). O local destas investigações é o elemento que deve ser seleccionado com particular atenção. Podem ser consideradas três situações : a fábrica instalada no país vendedor, a fábrica do mesmo tipo funcionando num país semelhante ao país comprador, uma fábrica de tecnologia similar que existe no país comprador.

97 Não é inútil proceder ao estudo ergonómico do dispositivo técnico conforme funciona nas condições supostamente satisfatórias do país vendedor. De facto, desconhece-se qualquer fábrica cuja visita não resulte numa vontade de melhorias. Mas, de uma forma mais específica, sabe-se que muitas fábricas construídas nos países em vias de desenvolvimento industrial são aí localizadas porque a mão-de-obra é considerada como sendo pouco exigente em termos de salários e condições de trabalho. Portanto, são, frequentemente, fábricas de produção de massa onde podem ser observadas más condições de trabalho

nos países de origem e recriadas noutro local. Podemos tentar recriar a fábrica sem os seus aspectos nocivos para os trabalhadores.

99 Nesta etapa, prestar-se-á atenção ao facto de que, demasiado frequentemente, o que é transferido com as máquinas é o conhecimento do engenheiro e do técnico, ou seja, o trabalho prescrito e não o trabalho real não reconhecido e fruto da experiência operária.

100 Assim, em 1980, Dongmo, com vista à preparação do estudo do funcionamento de uma empresa e respectivas condições de trabalho no seu país, os Camarões, obteve a autorização para analisar o funcionamento e condições de trabalho de uma fábrica semelhante em França. Trata-se de uma oficina automatizada da indústria alimentar em que as trabalhadoras são orientadas para as máquinas avariadas por painéis coloridos. Na realidade, Dongmo descobre que as trabalhadoras nunca olham para os painéis, pois estes nunca permitem prevenir as avarias. Elas próprias controlam, em permanência, as máquinas para tentar detectar as disfunções anteriores às avarias. Os engenheiros que conceberam o dispositivo de sinalização sabem que este não é eficiente, mas o serviço de formação estabeleceu o seu programa com base neste funcionamento teórico e inadequado. Se fosse entregue uma cópia desta oficina nos Camarões com o sistema teórico de organização e formação correspondentes, o contrato seria respeitado, mas a produtividade da oficina seria fraca e poder-se-ia, 
eventualmente, incriminar os trabalhadores locais, na realidade, mal informados e mal formados.

101 Assim, uma das dificuldades da transferência de tecnologia prende-se com o mau conhecimento dos quadros da empresa vendedora, não em relação ao dispositivo técnico, mas sim em relação à forma como o pessoal o consegue colocar eficientemente em funcionamento. A distância entre trabalho real e trabalho prescrito é uma fonte grave de mal-entendidos entre trabalhadores e órgão de controlo dos países desenvolvidos industrialmente e, mais ainda, no caso de transferência de tecnologia. Todavia, este tipo de dificuldades pode, por vezes, ser reduzido, conforme demonstrado por Dos Santos (1983) na sua comparação dos centros de controlo dos metros de Paris e Rio de Janeiro.

102 A fábrica do mesmo tipo que a fábrica a ser exportada, e que já funciona noutra região do país comprador ou num país vizinho, é, obviamente, um modelo particularmente interessante a estudar, independentemente de existirem aspectos geográficos ou antropométricos diferentes.

103 Ver-se-á em que medida o dispositivo técnico original e, principalmente, o seu manual de instruções foram transformados e quais as consequências destas mudanças na saúde dos trabalhadores, sua estabilidade, quantidade e qualidade da produção. É incontestável que este estudo apenas faz todo o sentido se for comparativo, tendo o mesmo estudo sido efectuado na fábrica instalada no país vendedor. De facto, o problema em ambas as situações de análise do trabalho reside na medição da distância que existe entre o trabalho prescrito e o trabalho realmente executado.

No caso muito frequente em que não existe no país comprador uma fábrica do mesmo tipo que a fábrica a ser transferida, a visita e o estudo de uma fábrica de tecnologia semelhante à que vai ser construída e instalada no país comprador -

e, se possível, na mesma região - constituem um elemento capital do diagnóstico. Permitem, em especial, ver de que forma o meio original foi modificado pela instalação da fábrica e respectivo sistema social, de que forma são organizados e utilizados os alojamentos, transportes, cantina, serviço médico, como podem ser realizados em oficina o funcionamento e a manutenção do sistema técnico e quais as soluções encontradas pelos responsáveis da fábrica, de forma mais ou menos empírica, para assegurar uma melhor adaptação do dispositivo técnico à situação local. Assim, os dados adquiridos pelo conhecimento da literatura, as conversas com os especialistas e a visita do local da futura fábrica irão ganhar todo o seu sentido. De facto, não se trata de adaptar o trabalho à situação anterior à instalação da fábrica, mas sim à situação posterior ao acontecimento capital para a região, constituído pela criação de um dispositivo industrial.

\section{III.3.2 - A participação em cada etapa da transferência}

A análise e a avaliação do projecto do ponto de vista geográfico e antropológico, assim como a reflexão crítica sobre as técnicas previstas serão, mais ou menos, aprofundadas consoante o grau de experiência dos ergonomistas, consoante o tempo e os meios de que irão dispor para preparar a sua participação activa na concepção e realização da fábrica transferida, tanto no período de selecção da tecnologia e tipo de edifício, como no período de compra das máquinas e dispositivos técnicos e respectiva 
implementação, como ainda na actividade de selecção e formação do pessoal e no tempo de colocação em funcionamento.

A selecção da tecnologia constitui uma etapa crítica do projecto. Por vezes, esta selecção é escamoteada porque o comprador quer ver reproduzida, no seu espaço, a mesma fábrica que viu no estrangeiro e admirou ou porque o vendedor representa apenas uma técnica cuja difusão pretende assegurar. Mais frequentemente, a questão encontra-se aberta e torna-se possível uma abordagem antropotecnológica. Por exemplo, existe actualmente no mundo uma grande quantidade de fábricas ultramodernas que estão fechadas porque a sua tecnologia requer pessoal especializado em informática ou automatismo, pessoal esse inexistente na população nacional e cuja vinda do estrangeiro é demasiado dispendiosa e difícil. Por vezes, é preciso uma certa coragem ao vendedor para chamar a atenção para este tipo de questão que pode ofender o comprador, principalmente se este último for um político e não um economista; relembra-se que estas considerações são importantes para reduzir a proporção dos investimentos e aumentar a dos salários. Ora, este tipo de orientação não é do interesse de todos.

108 A selecção do tipo de edifício provoca igualmente graves problemas na medida em que as condições climatéricas são, frequentemente, a causa principal de intolerância por parte dos trabalhadores. A selecção entre um edifício de paredes pesadas e estrutura específica que permita evitar a climatização e um edifício de paredes leves e concepção clássica que necessite de climatização traz, frequentemente, consequências posteriores. É incontestável que a segunda solução resulta na venda de vigotas de ferro, vidros e aparelhos de climatização, enquanto o edifício pesado pode ser, habitualmente, construído com os recursos locais, desde que a sua planta tenha sido cuidadosamente concebida. Vemos, demasiado frequentemente, em países tropicais, edifícios leves semelhantes aos dos países temperados e aceites, inicialmente, com uma climatização que nunca foi instalada ou que deixou de funcionar há muito tempo.

109 As condições térmicas são então aí execráveis e têm uma influência desastrosa na saúde dos trabalhadores e produtividade.

110 Vimos mais acima que existem excelentes documentos sobre as fábricas em países tropicais (Sen, 1981).

111 A compra das máquinas é um período crítico para a adaptação do trabalho ao homem. Pode parecer elementar relembrar que uma população asiana de homens com uma altura média de $158 \mathrm{~cm}$ ou mulheres com uma altura média de $148 \mathrm{~cm}$ não pode utilizar máquinas concebidas com base em normas antropométricas recolhidas em populações com uma altura média superior em $20 \mathrm{~cm}$. Em alguns casos, é possível resolver estes inconvenientes aquando da instalação das máquinas, colocando-as a um nível inferior ao do solo. Em muitas situações, devem ser exigidas modificações muito mais significativas aquando da compra das máquinas. Coloca-se, obviamente, a questão da existência, no catálogo dos fabricantes de máquinas, de modelos adaptados às populações de menor altura e cujos preços não sejam diferentes dos das máquinas semelhantes vendidas habitualmente. Seria possível efectuar observações semelhantes em relação às forças máximas a exercer, embora estas talvez difiram menos de uma população para outra, contrariamente às dimensões segmentares. No campo da simbolização, indicadores e instruções (job aids), é igualmente necessário obter dos fabricantes de máquinas que o sistema de comunicação seja acessível aos trabalhadores 
que não saibam ler em inglês, russo ou francês e até mesmo aos que não saibam ler de todo.

112 A grande abundância de mão-de-obra disponível, o facto de esta ser jovem e ter, por vezes, um bom nível geral de instrução podem criar uma ilusão perigosa, isto é, acreditar que uma selecção rigorosa do pessoal e um plano de formação amplo vão substituir a inadequação do dispositivo técnico em relação à população.

113 A selecção do pessoal tem, sem dúvida, um real interesse para eliminar 10 a $15 \%$ de candidatos demasiado marginais do ponto de vista físico ou mental. Ainda que para isso seja preciso dispor do pessoal médico e psicológico adequado e de uma validação local dos testes. Deve ser temida, em especial, a degradação rápida das capacidades dos trabalhadores sob o efeito das condições internas, mas, principalmente, externas à empresa (alojamento, família, saúde) cuja força é muito importante. Determinadas leis locais podem, além disso, favorecer a permanência na empresa de pessoas que se tornaram inaptas ou consideradas como tal.

114 A formação dos trabalhadores ocupa um lugar capital numa população pouco ou mal formada em relação às tarefas técnicas. A selecção deverá, portanto, ser efectuada numa perspectiva dinâmica para fornecer bons elementos com vista à formação. 0 grande risco prende-se aqui com a fuga permanente do pessoal formado para outras empresas desejosas de obter trabalhadores competentes, sem ter de arcar com os custos da formação. Os problemas pedagógicos são, por vezes, de natureza difícil, não os de natureza técnica, mas sim os associados ao sistema de valores industriais como a exactidão, precisão, fiabilidade, porque estas noções não correspondem à cultura tradicional enquanto não tiver sido realizada uma transposição cultural. Assim sendo, deverão ser obtidas boas ferramentas de formação no idioma vernacular dos trabalhadores e relacionadas com os modelos culturais locais.

115 Todavia, as dificuldades associadas ao pessoal vão surgir aquando da colocação em funcionamento da fábrica, em que convém estar envolvido.

116 Por um lado, poderão ser prestados serviços reais, diagnosticando e resolvendo as dificuldades que surgem diariamente, e, por outro lado, irão, rapidamente, vir ao de cima as consequências das negligências ou erros eventuais. Um dos factos mais marcantes que surge neste período reside na dificuldade de resolução por esforços humanos de algo mal previsto no dispositivo técnico.

\section{IV - Será a antropotecnologia exequível ?}

117 Tendo em conta que a antropotecnologia foi concebida como uma prática social, as questões que se colocam prendem-se com a sua exequibilidade e utilidade. Parece que é possível responder afirmativamente em ambos os casos.

118 Em contrapartida, é incontestável que ainda falta muito para reunir os elementos destinados a constituir a antropotecnologia. As deficiências mais nítidas parecem dizer respeito à metodologia antropotecnológica e determinados aspectos do próprio conteúdo da transferência.

119 A insuficiência da metodologia é, provavelmente, uma situação provisória associada ao carácter recente do tema de investigação. Todavia, existem dificuldades reais devido ao facto de ser necessário estabelecer colaborações estáveis entre as equipas dos países desenvolvidos industrialmente e países em vias de desenvolvimento industrial. De 
facto, é impossível realizar correctamente um estudo antropotecnológico sem uma contribuição significativa por parte de pessoas associadas ao desenvolvimento dos respectivos países, sem investigadores que possam comunicar, facilmente, com os trabalhadores no seu idioma vernacular e de acordo com as suas perspectivas culturais. Infelizmente, os investigadores pertencentes a países em vias de desenvolvimento industrial e dotados destas qualidades correm dois riscos: por um lado, serem altamente apreciados e rapidamente promovidos a cargos políticos ou administrativos ou, por outro lado, serem rejeitados por serem considerados política e socialmente perigosos. Apesar desses receios, não podemos deixar de expressar a nossa satisfação pela participação de vários jovens investigadores estrangeiros citados neste texto, pelo seu trabalho no Laboratório de Fisiologia do Trabalho e Ergonomia do CNAM e pela sua participação no seminário de antropotecnologia organizado todos os anos : Abrahão, de Godoy Garcia, Dos Santos (Brasil) ; Dongmo (Camarões) ; Meckassoua (África Central) ; Sahbi (Tunísia); Rubio (Filipinas).

Outro aspecto das deficiências da antropotecnologia remete, conforme acontece frequentemente, para as nossas próprias insuficiências. Referimos, várias vezes, neste texto, a mediocridade e ambiguidade teórica da organização do trabalho. De facto, perante as afirmações taylorianas, observam-se, essencialmente, contra-afirmações anti-taylorianas. As contradições entre estas críticas são consideráveis e raramente resolvidas, sendo, portanto, difícil formular um corpo coerente de recomendações práticas. Deve-se, sem dúvida, à natureza do tema situado no âmago do conflito social, mas também a uma elaboração insuficiente. Na transferência de tecnologia, a situação é ainda mais difícil devido às ligações estreitas entre as características da sociedade e a organização do trabalho. Vimos os inconvenientes de uma transferência completa da organização (ilhas) como os de uma transferência limitada às máquinas. Assim, existe, no próprio centro da antropotecnologia, um vasto campo de investigações tão antigo como a indústria, mas cujo interesse é renovado pelo actual período de transferência de tecnologia.

\section{BIBLIOGRAFIA}

Abrahão, J. (1983). Entrevista personal.

Amado, P. (1982). Entrevista personal.

Baker, S . l., \& Demayer, E.-M. (1978). Work capacity and nutrition. The American Journal of Nutrition, 32, 363.

Chapanis, A. (1975). Ethnic variables in human factors engineering. Baltimore : John Hopkins Univ. Press.

Chuairi da Silva, M.-R., \& Maluf, U. (1980). Otimizacao ergonornica nos tratos culturais da lavoura de cana de Açucar. Rio de Janeiro : I.S.O.P. Fundacao Getulio Vargas.

Courlet, C., Français, A., \& Judet, P. (1981). La semi-industrialisation. Cahiers IREP-Développement, 1. 
Dejours, C. (1981). Travail, usure mentale. Paris : Le Centurion.

Dongmo, S. (1980). Entrevista personal.

Dos Santos, N. (1983). La fiabilité humaine dans le contrôle de processus en temps réel, analysé ergonomique en vue d'un transfert de technologie. Tese DEA de Ergonomía. Paris, CNAM.

Godelier, M. (1982). Préface. In B. Doray, Le taylorisme, folie rationnelle. Paris : Dunod.

Godoy Garcia, A. de (1982). Entrevista personal.

Gourou, P. (1982). Terres de bonne espérance : le monde tropical. Paris: Plon.

Krishna, A. (1980). The economic development on India. Scientific American, 243(3), 134-143.

Lacoste, Y. (1982). Géographie du sous-développement. Paris : PUF.

Lévi-Strauss, C. (1980, Octubre 25). Entrevista sobre Japón. Matin-Magazine.

Mallet, S. (1964). La nouvelle classe ouvrière. Paris :Seuil.

Meckassoua, K. (1983). Etude comparée des activités de régulation dans le cadre d'un transfert de technologie (brasserie). Tese de Doutoramento em Ergonomia. Paris, CNAM.

Miske, A.-B. (1981). Lettre ouverte aux élites du Tiers-monde. Paris : Le Sycomore.

Montmollin, M. (de) (1967). Les systèmes hommes-machines. Paris : PUF.

Ombredane, A., \& Faverge, J.-M. (1956). L'analyse du travail. Paris : PUF.

Rubio, C. (1982). Entrevista personal.

Sahbi, N. (1982). Intérêt des mesures anthropométriques dans le transfert de technologie. Conferencia en el XVIII Congreso de la Sociedad de Ergonomía de la Lengua Francesa, Paris.

Sahbi, N. (1983). Conditions de travail et Production. Memória de ergonomista. Paris, CNAM.

Sen, R. (1981). Certain ergonomic principles in the design of factoriel in hot climates. Informe del simposio tripartito sobre la seguridad, la salud y las condiciones laborales. Genève: BIT.

Sinaïko, H.-W. (1975). Verbal factors in human engineering. In A. Chapanis (Ed.), Ethnic variables in human factors engineering. Baltimore : John Hopkins Univ, Press.

Tort, B. (1974). Bilan de l'apport de la recherche scientifique à l'amélioration des conditions de travail, Laboratorio de Fisiología del Trabajo y de Ergonomía, Informe ํㅜ 47, Paris, CNAM.

Verhagen, P., Bervoets, R., Debrabandere, G., Millet, F., SanterMans, G., Syuyck, M., Vanpermoere, D., \& Willems, G. (1975). Direction of movement stereotypes in different cultural group. In A.

Chapanis (Ed.), Ethnic variables in human factors engineering. Baltimore: John Hopkins Univ. Press.

Voets, F. J. A. (1975). Overcoming the language barrier with foreign workers. In A. Chapanis (Ed.), Ethnic variables in human factors engineering. Baltimore : John Hopkins Univ. Press. 